\title{
The potential of pulsed low intensity ultrasound to stimulate chondrocytes matrix synthesis in agarose and monolayer cultures
}

\author{
Natalie M. Vaughan · James Grainger • \\ Dan L. Bader • Martin M. Knight
}

Received: 18 May 2010/Accepted: 11 September 2010/Published online: 12 October 2010

(C) The Author(s) 2010. This article is published with open access at Springerlink.com

\begin{abstract}
Pulsed low intensity ultrasound (PLIUS) has been used successfully for bone fracture repair and has therefore been suggested for cartilage regeneration. However, previous in vitro studies with chondrocytes show conflicting results as to the effect of PLIUS on the elaboration of extracellular matrix. This study tests the hypothesis that PLIUS, applied for $20 \mathrm{~min} /$ day, stimulates the synthesis of sulphated glycosaminoglycan (sGAG) by adult bovine articular chondrocytes cultured in either monolayer or agarose constructs. For both culture models, PLIUS at either 30 or $100 \mathrm{~mW} / \mathrm{cm}^{2}$ intensity had no net effect on the total sGAG content. Although PLIUS at $100 \mathrm{~mW} / \mathrm{cm}^{2} \mathrm{did}$ induce a $20 \%$ increase in SGAG content at day 2 of culture in agarose, this response was lost by day 5 . Intensities of 200 and $300 \mathrm{~mW} / \mathrm{cm}^{2}$ resulted in cell death probably due to heating from the ultrasound transducers. The lack of a sustained up-regulation of sGAG synthesis may reflect the suggestion that PLIUS only induces a stimulatory effect in the presence of a tissue injury response. These results suggest that PLIUS has a limited potential to provide an effective method of stimulating matrix production as part of a tissue engineering strategy for cartilage repair.
\end{abstract}

Keywords LIPUS · PLIUS · Cartilage ·

Glycosaminoglycan · Ultrasound

N. M. Vaughan · J. Grainger · D. L. Bader · M. M. Knight ( $\square)$

School of Engineering and Materials Science, Queen Mary University of London, Mile End Road, London E1 4NS, UK

e-mail: m.m.knight@qmul.ac.uk

\section{Introduction}

Pulsed low intensity ultrasound (PLIUS), also known as low intensity pulsed ultrasound (LIPUS), has clinically been shown to enhance the healing of fresh fractures and bony non-unions $[16,22]$. The mode of action is unclear, although exciting new studies indicate that ultrasound activates the canonical Wnt signalling pathway which is important for osteoblast function [34]. Other studies suggest that ultrasound may stimulate bone healing processes such as endochondral ossification [37, 41], involving the earlier expression of cartilage specific genes [44]. Consequently, PLIUS may also be beneficial for cartilage regeneration either in vivo or as part of an in vitro tissue engineered approach $[6,17,29]$.

The acoustic pressure waves produced by PLIUS can be considered as high-frequency micromechanical perturbations that may have a direct mechanical effect on exposed cells. Indeed, the resulting cellular and intracellular changes may be similar to those seen with more physiological low frequency cyclic compression of chondrocytes in cartilage explants [12] or biomaterial scaffolds [5, 24, 28]. Several in vitro studies have been undertaken to characterise the effects of PLIUS on chondrocytes in both monolayer and 3D model systems. These studies report upregulation of aggrecan and collagen II genes [30, 35, 45], GAG synthesis [20, 32], calcium signalling [36], and integrin expression [18]. However, conflicting reports suggest that PLIUS induces, at best, a transient effect on chondrocyte culture systems in terms of aggrecan gene expression [46], and GAG and collagen II production $[17,21]$. Furthermore, a study involving the implantation of a tissue-engineered scaffold into nude mice indicated that PLIUS had no effect on cartilage matrix production, as assessed by histological staining, and an inhibitory effect 
on neocartilage maturation in terms of collagen II gene expression and tissue biomechanics [10]. The literature is therefore ambiguous regarding the influence of PLIUS on articular chondrocytes and the possible acceleration of chondrogenic pathways.

This study examines the influences of PLIUS on adult articular chondrocytes cultured both in monolayer and within the well-established 3D agarose model. Initial studies investigated the effect of PLIUS intensity on the viability of chondrocytes within the agarose gel. Thereafter, two different intensities, 30 and $100 \mathrm{~mW} / \mathrm{cm}^{2}$, were selected to test the hypothesis that PLIUS stimulates the synthesis and elaboration of sGAG over a 16-day culture period, and that this response is influenced by the intensity of the ultrasound. The synthesis of sGAG was quantified by measuring both the total sGAG content, using the DMB assay, and the synthesis of new sGAG, using incorporation of radiolabelled $\mathrm{SO}_{4}$.

\section{Materials and methods}

\subsection{Preparation of chondrocyte cultures}

Chondrocytes were isolated from the metacarpophalangeal joint of skeletally mature, 18-24 month old steers and seeded in agarose using a well-established method [24]. Culture media (DMEM $+20 \%$ FCS) consisted of high glucose Dulbecco's Modified Eagles Medium (DMEM) supplemented with L-glutamine $(2 \mu \mathrm{M})$, L-ascorbate $(0.85 \mu \mathrm{M})$, penicillin $(5 \mu \mathrm{g} / \mathrm{ml})$, streptomycin $(5 \mu \mathrm{g} / \mathrm{ml})$, HEPES $(20 \mathrm{mM})$ and $16.1 \%(\mathrm{v} / \mathrm{v})$ foetal calf serum (FCS). All reagents were from Sigma-Aldrich UK, unless otherwise stated. Full depth cartilage from the proximal surface of the joint was extracted and sequentially digested at $37^{\circ} \mathrm{C}$ for $1 \mathrm{~h}$ in 700 units $/ \mathrm{ml}$ of pronase (Type E, BDH Ltd., UK) followed by $16 \mathrm{~h}$ in 100 units/ml of collagenase (Type XIA), both prepared in DMEM + FCS. The explant digest was passed through a cell sieve, and the resulting cell suspension was washed twice with fresh DMEM + FCS. Thereafter, cell number and viability were assessed using trypan blue and a haemocytometer. In total, data were collected from six separate chondrocyte isolations, with cells pooled from four to six individual joints for each isolation.

For 3D agarose cultures, the isolated cells were seeded in $3 \%$ low gelling agarose (type VII) at $4 \times 10^{6}$ cells $/ \mathrm{ml}$. Using a positive displacement pipette, each well of a standard six-well culture plate was filled with $3.3 \mathrm{ml}$ of the cell-agarose suspension to yield a layer of cell-agarose gel $3 \mathrm{~mm}$ in height. Subsequent to gelation at $4^{\circ} \mathrm{C}$ for $20 \mathrm{~min}$, the cell-agarose layer in each well was covered with
$6.6 \mathrm{ml}$ of DMEM + FCS and cultured for $24 \mathrm{~h}$ at $37^{\circ} \mathrm{C}$ and $5 \% \mathrm{CO}_{2}$ before experimentation. For monolayer cultures, cells were seeded directly into the wells of a standard six-well culture plate at a density of $100 \times 10^{3}$ cells $/ \mathrm{cm}^{2}$ as used previously [35]. Each well, containing approximately 1 million cells, was filled with $6 \mathrm{ml}$ of DMEM + FCS. All the cultures were maintained at $37^{\circ} \mathrm{C}$ and $5 \% \mathrm{CO}_{2}$ within a humidified cell culture incubator with media changed every $1-3$ days.

\subsection{PLIUS system}

PLIUS was generated using a calibrated Exogen system provided by Smith and Nephew Inc. (York, UK). This delivered an ultrasound signal with Spatial Average and Temporal Average (SATA) intensities between 30 and $300 \mathrm{~mW} / \mathrm{cm}^{2}$, and a sinusoidal waveform of frequency of $1.5 \mathrm{MHz}$ with a $200-\mu$ s pulse burst repeating at $1.0 \mathrm{kHz}$, as previously described [33]. The ultrasonic driver box controlled six transducers mounted in a frame specifically for use with a standard six-well culture plate [35]. PLIUS was produced at the transducers and transmitted through the bottom of the wells of a six-well plate with the use of coupling gel (Exogen, Piscataway, USA). For all the studies, PLIUS stimulation was applied once a day for a 20-min period.

\subsection{Influence of PLIUS intensity on cell viability}

Chondrocyte-agarose gels were cultured for 9 days, during which they were subjected to $20 \mathrm{~min}$ of PLIUS once a day at SATA intensities of either 30, 100, 200 or $300 \mathrm{~mW} / \mathrm{cm}^{2}$. For assessment of cell viability, a single cylindrical construct, $6 \mathrm{~mm}$ in diameter, was removed from the central region of each well at the end of the 9-day culture period. The construct was cut longitudinally and incubated for $45 \mathrm{~min}$ in $0.6 \mathrm{ml}$ of DMEM + FCS supplemented with Calcein-AM ( $5 \mu \mathrm{M}$, Molecular Probes, UK) and Ethidium homodimer-2 (5 $\mu \mathrm{M}$, Molecular Probes, UK) to label the live and dead cells, respectively. Thereafter, each half construct was washed and mounted with its cut surface on a cover slip and visualised with a fluorescent microscope (Eclipse, Nikon, Kingston-upon-Thames, UK) with a $\times 20$ objective. Viability was recorded by a systematic sampling of the construct, using a standard eye piece graticule sampling area of $0.5 \times 0.25 \mathrm{~mm}^{2}$. Adjacent sampling areas were examined, profiling from the top of each construct down to the base closest to the PLIUS transducer. The number of live (green) and dead (red) cells were counted in each sampling area and the percentage viability calculated. The procedure was repeated $(n=3)$ for each construct. 


\subsection{Influence of PLIUS on sGAG production}

To quantify the influence of PLIUS on elaboration of sGAG, chondrocytes in both agarose and monolayer cultures were subjected daily, to a 20-min period of PLIUS at a SATA intensity of 30 or $100 \mathrm{~mW} / \mathrm{cm}^{2}$. Initial exposure of the agarose constructs occurred after $24 \mathrm{~h}$ of culture. By contrast, monolayer cultures were first incubated for $96 \mathrm{~h}$ to enable cells to become fully attached to the plastic substrate, in keeping with previous studies by Parvezi et al. [35]. Non-stimulated controls in separate six-well plates, were identically treated but without exposure to PLIUS.

Media were changed every 1-3 days and frozen for subsequent analysis. For agarose cultures, 6-mm-diameter cylindrical constructs $(n=6)$ were removed from the centre of a single well on days 1, 2, 5, 9, 12 and 16 and stored frozen. At the end of each experiment, the constructs were thawed and digested in 560 units $/ \mathrm{ml}$ papain and 1000 units/ml agarase (both Sigma-Aldrich, Poole, UK). For monolayer cultures at days 4, 6 and 8, the media were removed, and the cell extract processed separately, following protocols described by Parvezi et al. [35].

The entire procedure for both PLIUS intensity settings, was repeated using separate chondrocyte isolations $(n=3$ for agarose and $n=2$ for monolayer). At each time point, data was normalised to the corresponding controls to account for any inherent biological variation between the animals used in the replicate experiments.

\subsection{Biochemical analysis}

Total sGAG contents in the agarose constructs, the monolayer samples and all the associated media were determined using the DMB method [11]. The sGAG values for the media were summed to give cumulative sGAG released into the media. In order to estimate the amount of sGAG released from each cylindrical agarose construct, the cummulative level of sGAG in the media for each well was multiplied by the ratio of the cross-sectional area of the agarose construct divided by the area of the well.

\subsection{Radioisotope incorporation}

Radioisotope incorporation assays were used to determine the rate of sGAG synthesis over specific 24-h time periods following established protocols [24]. For agarose constructs on days $1,4,8,11$ and 15 , the media were removed from the wells and replaced with fresh media supplemented with $10 \mu \mathrm{Ci} / \mathrm{ml}^{35} \mathrm{SO}_{4}$ (Amersham Biosciences, UK). The media were removed after $24 \mathrm{~h}$ and stored frozen. After $24 \mathrm{~h}$, 6-mm-diameter agarose constructs were removed, stored frozen until the end of the experiment and then digested with papain and agarase as described above.
Similarly, for monolayer cultures ${ }^{35} \mathrm{SO}_{4}$ supplement media were added at days 1, 4, 8, 11 and 15 . After $24 \mathrm{~h}$, the media and monolayer extract samples were removed and frozen before analysis.

Alcian blue precipitation onto filters (Millipore, Watford, UK) was used to determine the incorporation of ${ }^{35} \mathrm{SO}_{4}$ into the newly synthesised sGAG in the agarose digest, the monolayer samples and all the associated media. The incorporation was normalised to the total DNA measurements calculated using the Hoescht 33258 assay as previously described [1].

\section{Results}

\subsection{Influence of PLIUS intensity on cell viability}

After 9 days in culture, cell viability for agarose constructs was greater than $85 \%$ throughout the depth of the construct. PLIUS at SATA intensities of $30-100 \mathrm{~mW} / \mathrm{cm}^{2}$ had no effect on cell viability (Fig. 1). However, at SATA intensities of 200 and $300 \mathrm{~mW} / \mathrm{cm}^{2}$, a significant loss in viability occurred towards the bottom of the agarose constructs. Thus, at a SATA intensity of $300 \mathrm{~mW} / \mathrm{cm}^{2}$, there was $100 \%$ cell death in the agarose, adjacent to the PLIUS transducer.

\subsection{Influence of PLIUS on sGAG synthesis in agarose culture}

The temporal change in total sGAG content are shown in Fig. 2 for chondrocytes in agarose constructs exposed to

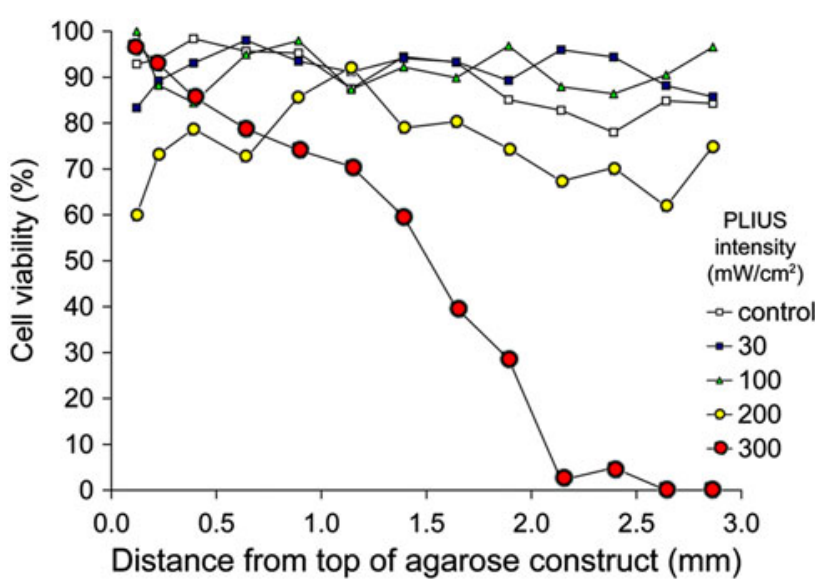

Fig. 1 Cell viability profiles through chondrocyte-agarose gels exposed to PLIUS for $20 \mathrm{~min} /$ day for 9 days. PLIUS was applied at SATA intensities of 30, 100, 200 and $300 \mathrm{~mW} / \mathrm{cm}^{2}$. Controls were not exposed to PLIUS. Viability is expressed as the percentage of viable cells per field of view for adjacent fields of view throughout the $3 \mathrm{~mm}$ thickness of the agarose gel. Data points represent mean viability values $(n=6)$ 
PLIUS at 30 (Fig. 2a) and $100 \mathrm{~mW} / \mathrm{cm}^{2}$ (Fig. 2b) with corresponding control values. Cummulative release of sGAG into the associated culture media is also presented. For all treatment groups, there was a steady synthesis of sGAG over the 16-day culture period, with approximately $80 \%$ retained within the agarose construct and the rest released to the associated culture media. Statistical analysis was conducted using the data from three repeat experiments and a total of 14 bovine joints. The application of PLIUS at a SATA intensity of $30 \mathrm{~mW} / \mathrm{cm}^{2}$, showed no statistically significant effect on the total synthesis of sGAG or the retention within the agarose constructs at any of the time points $(P>0.05$, paired two-tailed $T$-test $)$ (Fig. 2c). Similarly, at $100 \mathrm{~mW} / \mathrm{cm}^{2}$, PLIUS had no effect with the exception of a $20 \%$ increase in total sGAG content at day $2(P<0.05)$ (Fig. $2 \mathrm{c})$.

The incorporation of $\mathrm{SO}_{4}$ into newly synthesised sGAG for chondrocytes exposed to 30 and $100 \mathrm{~mW} / \mathrm{cm}^{2}$ is presented graphically in Fig. 3. At days 2, 5, 9 and 16, but not day $12, \mathrm{SO}_{4}$ incorporation over the previous $24 \mathrm{~h}$ was significantly reduced in cells exposed to $30 \mathrm{~mW} / \mathrm{cm}^{2}$ PLIUS compared to controls $(P<0.05)$. By contrast, PLIUS at $100 \mathrm{~mW} / \mathrm{cm}^{2}$ was associated with statistically significant increases in $\mathrm{SO}_{4}$ incorporation measured at day 2 and day 16. At all other time points, differences were not statistically significant. Studies conducted with PLIUS applied twice a day showed no difference from the once-aday protocol used here (data not shown) [42].

\subsection{Influence of PLIUS on sGAG synthesis \\ in monolayer culture}

Chondrocytes in monolayer synthesised sGAG, with the majority, approximately $50-70 \%$, released to the media. There were no statistically significant differences, at any time point, in the total sGAG levels between control cultures and those exposed to PLIUS at either 30 or $100 \mathrm{~mW} /$ $\mathrm{cm}^{2}$ (Fig. 4). Similarly, PLIUS has no statistically significant effects on $\mathrm{SO}_{4}$ incorporation at any of the time points studied (Fig. 5).

\section{Discussion}

The majority of previous studies examining the effects of PLIUS on chondrocytes have used monolayer cultures $[7,18,35,36]$. However, such an approach has a number of biological and biophysical limitations. First, chondrocytes in monolayer are known to lose their chondrocytic phenotype and become more fibroblastic in nature, with associated alterations in cytoskeletal organisation and changes in matrix synthesis. In addition, monolayer cultures may be more susceptible to artefacts associated with
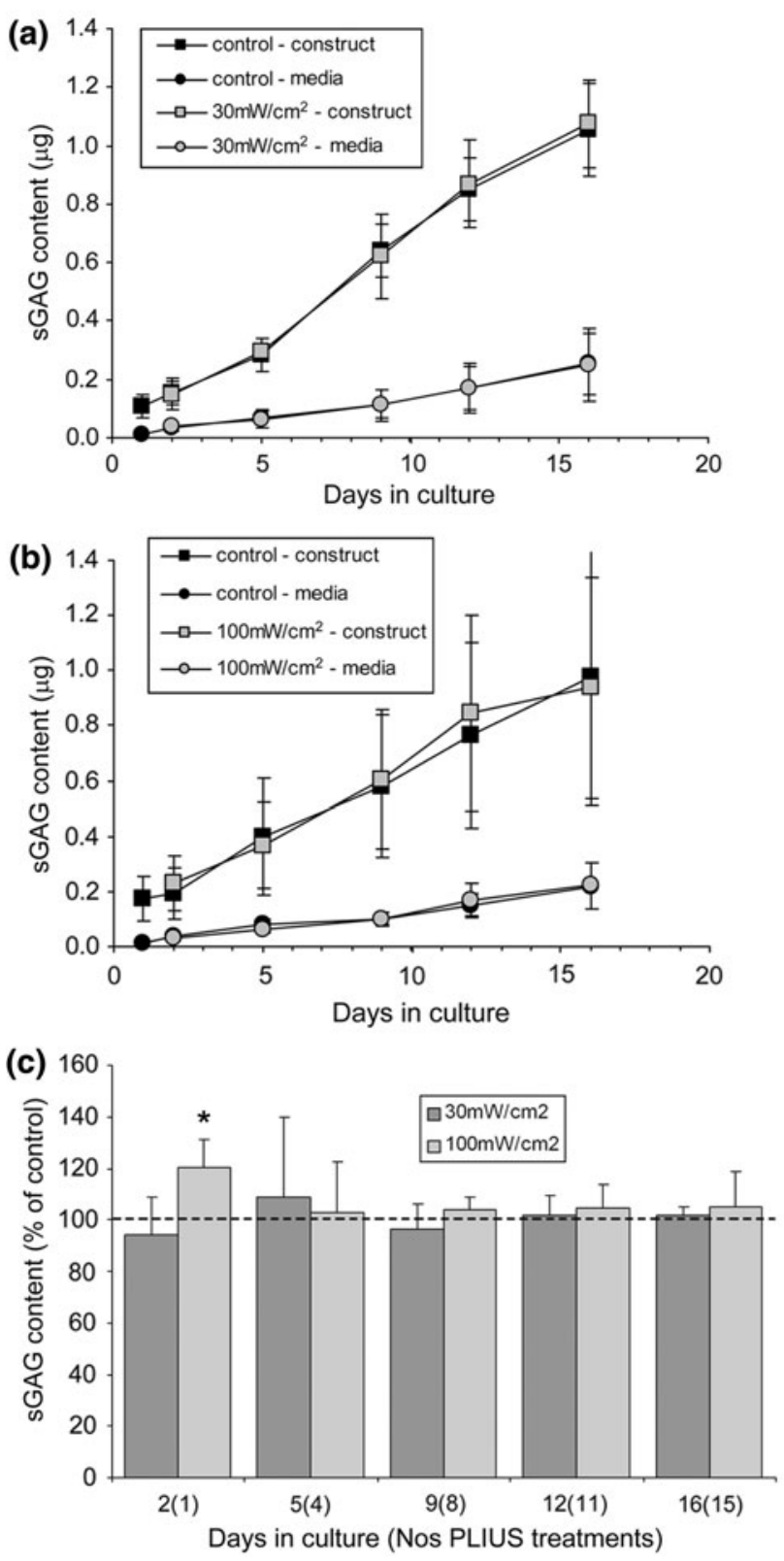

Fig. 2 Effect of PLIUS on cumulative sGAG content produced by chondrocytes over a 16-day culture period in agarose. PLIUS was applied for 20 min each day from day 1. Data plotted separately for sGAG retained within agarose construct and released to associated culture media for control cells and those exposed to PLIUS at 30 (a) and $100 \mathrm{~mW} / \mathrm{cm}^{2}$ (b). Data for PLIUS treated chondrocyteagarose constructs has also been plotted as a percentage of that measured for corresponding untreated controls (c). Values represent mean \pm standard deviation for three separate repeat experiments. Statistically significant differences are indicated at $* P<0.05$

PLIUS. For example, heating occurs due to attenuation of the ultrasound in the plastic encasing the transducers and the base of the cell culture six-well plate. Indeed, a previous study has reported a slight increase in the global temperature of the media within a single well [14]. Whilst this temperature rise may not be sufficient to activate heat 


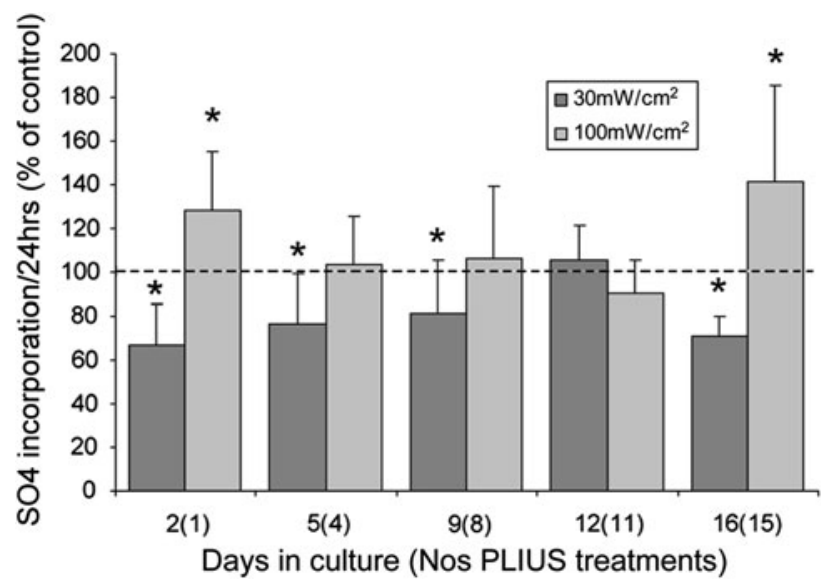

Fig. 3 Effect of PLIUS at 30 and $100 \mathrm{~mW} / \mathrm{cm}^{2}$ on $\mathrm{SO}_{4}$ incorporation over $24 \mathrm{~h}$ normalised to corresponding untreated controls (100\%) for chondrocytes cultured in agarose for up to 16 days. PLIUS was applied for $20 \mathrm{~min}$ each day from day 1. Values represent mean \pm standard deviation for 14 replicate specimens from two separate experiments. Statistically significant differences are indicated at $* P<0.05$

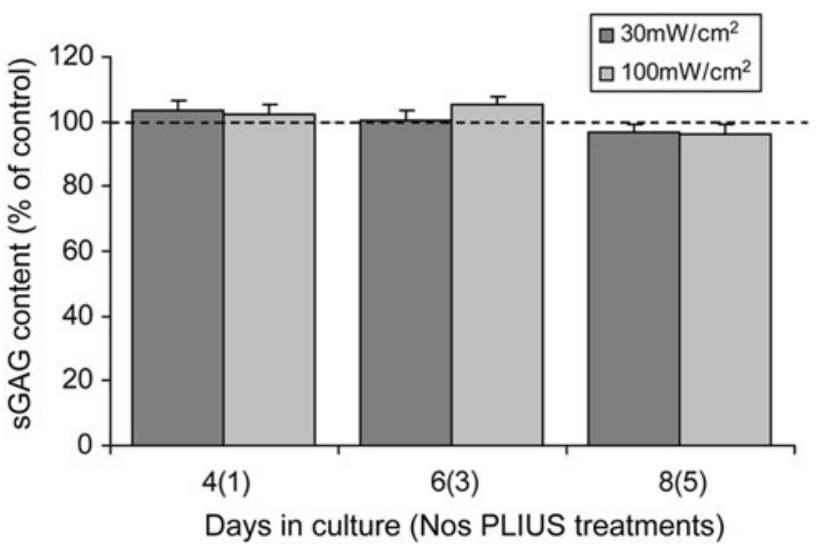

Fig. 4 Effect of PLIUS at 30 and $100 \mathrm{~mW} / \mathrm{cm}^{2}$ on total cumulative sGAG content (cell extract plus media) produced by chondrocytes over an 8-day culture period in monolayer. PLIUS was applied for 20 min each day from day 3. Data for PLIUS treated chondrocytes in monolayer has been plotted as a percentage of that measured for corresponding untreated controls. Values represent mean \pm standard deviation for 12 replicate specimens from two separate experiments. There were no statistically significant differences between PLIUStreated constructs and corresponding controls

shock proteins or lead to cell death, it may alter the metabolism of the cells directly adhered to cell culture plastic. Another potential artefact with monolayer cultures is the development of standing waves caused by constructive interference associated with the reflection of the ultrasound between the air-media interface and the mediaplastic interface [14]. Standing waves may generate fluid shear forces, which are known to modulate chondrocyte metabolism and matrix synthesis [23]. In addition, the reflection of the ultrasound signal back into the transducer

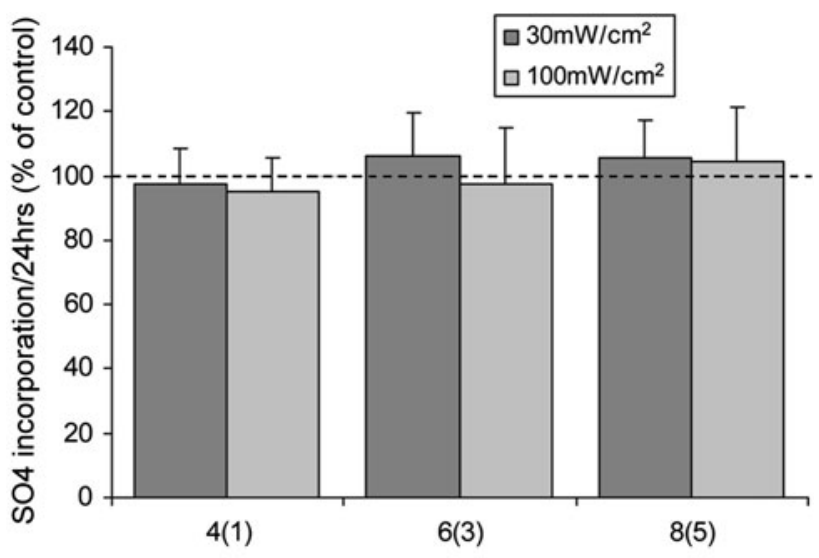

Days in culture (Nos PLIUS treatments)

Fig. 5 Effect of PLIUS at 30 and $100 \mathrm{~mW} / \mathrm{cm}^{2}$ on $\mathrm{SO}_{4}$ incorporation over $24 \mathrm{~h}$ normalised to corresponding untreated controls (100\%) for chondrocytes over an 8-day culture period in monolayer. PLIUS was applied for 20 min each day from day 3. Data for PLIUS treated chondrocytes in monolayer has been plotted as a percentage of that measured for corresponding untreated controls. Values represent mean \pm standard deviation for 12 replicate specimens from two separate experiments. There were no statistically significant differences between PLIUS-treated constructs and corresponding controls

may increase the heating effects. Thus, some studies have employed PLIUS systems in the absence of an air-media interface to ensure improved control of the ultrasound signal, as well as using ultrasound-absorbing material to eliminate multiple reflections $[15,19,30,46]$.

There is, therefore, increasing interest in understanding the effects of PLIUS on chondrocytes seeded within 3D scaffolds such as agarose, alginate and chitosan. Of these, the chondrocyte-agarose model has been particularly well characterised and is extensively used for examining the effect of mechanical stimulation on chondrocytes. Chondrocytes cultured in agarose adopt a rounded morphology necessary for the maintenance of chondrocytic phenotype, as shown by the synthesis of cartilage-specific aggrecan proteoglycan and type II collagen [2, 3]. For this reason, agarose has also been proposed as a scaffold for cartilage tissue engineering $[28,40]$ with encouraging clinical outcomes using chondrocytes embedded in a composite agarose-alginate hydrogel [39]. Hence, this study investigated the effect of PLIUS on isolated chondrocytes seeded in agarose gel cast within a six-well plate mounted above an array of ultrasound transducers. The use of agarose is relevant both as a potential tissue-engineered scaffold and as a model for examining the therapeutic benefit of ultrasound for chondrocytes within a variety of $3 \mathrm{D}$ scaffolds proposed for cartilage tissue engineering. Comparative studies were also conducted using adult bovine chondrocytes cultured in monolayer following protocols described by Parvizi et al. [35]. 
Previous studies investigating the influence of PLIUS have generally used a SATA intensity of $30 \mathrm{~mW} / \mathrm{cm}^{2}$ which has been shown to be effective for treatment of bone fractures. However, modelling studies reveal that the exposure of knee joints to ultrasound at the clinical intensity of $30 \mathrm{~mW} / \mathrm{cm}^{2}$ is likely to result in a tissue level intensity of only $10 \mathrm{~mW} / \mathrm{cm}^{2}$ [43]. Among those studies that report that PLIUS up-regulates chondrocyte metabolism, there is some disagreement as to whether intensity modulates this effect. Thus, some studies report a directly proportional relationship between intensity and cell activity $[6,17]$, others suggest that lower intensities are more effective [40, 46], while some other studies indicate little difference between intensity levels [35] or no effect at all $[6,10]$. This study demonstrated that viability in agarose was maintained at SATA intensities up to $100 \mathrm{~mW} / \mathrm{cm}^{2}$, but was reduced at 200 and $300 \mathrm{~mW} / \mathrm{cm}^{2}$, particularly for those cells located closer to the underlying ultrasound transducer (Fig. 1). This suggests that the cell death may be the result of attenuation heating in the transducer and/or the six-well plate, although other mechanisms, such as cavitation, cannot be excluded. Based on these results, all the subsequent studies were restricted to two intensity levels, namely 30 and $100 \mathrm{~mW} / \mathrm{cm}^{2}$.

Preliminary studies found that PLIUS at either 30 or $100 \mathrm{~mW} / \mathrm{cm}^{2}$ had no effect on cell proliferation in either monolayer or agarose cultures as assessed by total DNA content and incorporation of $\left[{ }^{3} \mathrm{H}\right]$ thymidine (data not shown) [42]. This is in agreement with the majority of previous studies. In terms of the synthesis of sGAG, this study revealed that PLIUS at $30 \mathrm{~mW} / \mathrm{cm}^{2}$ for $20 \mathrm{~min} /$ day, had no stimulatory effect on adult bovine articular chondrocytes cultured in either agarose gel (Figs. 2, 3) or monolayer (Figs. 4, 5). Indeed, PLIUS significantly reduced the rate of $\mathrm{SO}_{4}$ incorporation for cell-agarose constructs at days 2, 5, 9 and 16, although this was not associated with a reduction in total sGAG content. At $100 \mathrm{~mW} / \mathrm{cm}^{2}$ the application of PLIUS to cells in agarose only induced a statistically significant increase in $\mathrm{SO}_{4}$ incorporation with an associated increase in sGAG content, but only at day 2 . For chondrocytes cultured in monolayer, PLIUS at $100 \mathrm{~mW} / \mathrm{cm}^{2}$ had no effect on sGAG synthesis (Figs. 4, 5).

These findings are in agreement with a few previous studies suggesting that PLIUS has, at best, a minimal stimulatory effect on chondrocyte matrix production $[17,21,46]$. However, the data appear to conflict with the other studies which suggest that ultrasound induces an up-regulation of chondrocyte aggrecan gene expression, incorporation of $\mathrm{SO}_{4}$ into the newly formed sGAG, and downstream sGAG accumulation [21, 33, 35, 40, 44]. In particular, the pioneering study by Parvizi et al. [35] is frequently cited as showing that PLIUS stimulates matrix production by rat chondrocytes in monolayer. However, in agreement with this study, Parvizi et al. report no statistically significant difference in sGAG content between PLIUS-treated and control cultures. This previous study did find a significant difference in the rate of change of sGAG content, but this appears to be due to the lower initial level of sGAG in the PLIUS treated samples. Nevertheless, in contrast to this study, similar experiments with bovine patella chondrocytes in monolayer show $\mathrm{SO}_{4}$ incorporation increased approximately twofold after 3-5 days of PLIUS exposure at $10 \mathrm{~min} /$ day [20]. The difference may be due to the use of a higher ultrasound intensity of $580 \mathrm{~mW} / \mathrm{cm}^{2}$, which did not result in cell death, possibly due to the use of a water bath system. The stimulatory effect in this and other studies might also be attributed to the utilisation of different cell types. Indeed, studies reporting a stimulatory effect of PLIUS have frequently employed neonatal, embryonic and mesenchymal stem cells (MSCs) [9, 32, 46]. Such populations are likely to be more metabolically active than skeletally mature cells, such as those used in the present and other studies, which have reported minimal or no stimulatory effect of PLIUS [6, 10]. This is supported by studies showing that human articular chondrocytes from older donors are less responsive to PLIUS stimulation in agarose compared to cells from younger donors [40]. However, the use of skeletally mature cells is relevant to the clinical situation, where the majority of patients seeking surgical intervention for cartilage injury are adults. Tissue engineering strategies would preferentially utilise autologous adult cells although an alternative approach might be to employ PLIUS to stimulate autologous MSCs into chondrogenesis. Indeed it has been reported that PLIUS enhances chondrogenic differentiation [25] and stimulates proteoglycan and collagen expression for human MSCs cultured in 3D scaffolds [38].

In this study, there was notable variation between replicate experiments with different cell isolations. Interestingly, Kopakkala-Tani et al. also reported that PLIUS induced different effects on cells from different animals [20]. This variability may reflect important person to person variability in the benefit provided by any therapeutic approach using autologous cells. Although it is not clear as to what is responsible, one possibility is that ultrasound is only effective in tissue from a damaged or inflamed joint. This is supported by the fact that PLIUS is very effective in the treatment of fracture non-unions [4, 16, 22], but has been shown to have no effect on increasing bone mass in osteoporosis where there is no injury response [26]. Similarly, ultrasound is reported to have a greater effect on osteoarthritic human chondrocytes in monolayer compared to cells isolated from nonosteoarthric tissue from the same joint, although the study found no effect in cartilage explants [21]. In addition, 
animal models show that PLIUS enhances healing of an osteochondral injury [8] and reduces the severity and progression of osteoarthritis with an increase in collagen II gene expression [13, 31]. The mechanism may involve Rac1 and Wnt signalling which are activated by PLIUS and involved in membrane protrusion and cell migration associated with mammalian wound healing [27, 34]. Thus, as previously suggested, the therapeutic benefit of PLIUS, may be dependent on the presence of an injury or wound healing response involving Rac1-mediated cell migration. Indeed, this may explain the conflicting results from previous studies which might occur because of differing degrees of injury response present within different in vitro or in vivo model systems.

In conclusion, this study reveals that PLIUS at $30 \mathrm{~mW} /$ $\mathrm{cm}^{2}$ had no net effect on the synthesis of sGAG by adult bovine articular chondrocytes cultured in either agarose or monolayer culture. However, at $100 \mathrm{~mW} / \mathrm{cm}^{2}$, PLIUS induced an initial transient up-regulation of $\mathrm{SO}_{4}$ incorporation and sGAG content in agarose constructs. This initial stimulatory effect of $100 \mathrm{~mW} / \mathrm{cm}^{2}$ PLIUS, may be associated with some form of transient injury response caused by enzymatic isolation and seeding in agarose. This may provide a limited window of opportunity to stimulate SGAG production, at SATA intensities above $30 \mathrm{~mW} / \mathrm{cm}^{2}$. These findings have important implications for the therapeutic potential of PLIUS for adult articular cartilage regeneration and tissue engineering as well as understanding the potential mechanisms through which PLIUS may activate a healing response in other systems.

Acknowledgments We are grateful to the EPSRC and to Smith and Nephew Plc who provided funding for this study in the form of a $\mathrm{PhD}$ CASE Studentship for Natalie Vaughan. We are particularly grateful to Dr. Robin Chivers for his support with these studies during his time at Smith and Nephew. We would like to thank Danny Neighbour, within the School of Engineering and Materials Science at QMUL, for the design and manufacture of the electronic timer used for controlling the PLIUS system.

Open Access This article is distributed under the terms of the Creative Commons Attribution Noncommercial License which permits any noncommercial use, distribution, and reproduction in any medium, provided the original author(s) and source are credited.

\section{References}

1. Araki T, Yamamoto A, Yamada M (1987) Accurate determination of DNA content in single cell-nuclei stained with Hoechst33258 fluorochrome at high salt concentration. Histochemistry 87:331-338

2. Aydelotte M, Keuttner KE (1988) Differences between subpopulations of cultured bovine articular chondrocytes. I. Morphology and cartilage matrix production. Connect Tissue Res 18:205-222
3. Aydelotte MB, Greenhill RR, Kuettner KE (1988) Differences between sub-populations of cultured bovine articular chondrocytes. II. Proteoglycan metabolism. Connect Tissue Res 18:223-234

4. Azuma Y, Ito M, Harada Y, Takagi H, Ohta T, Jingushi S (2001) Low-intensity pulsed ultrasound accelerates rat femoral fracture healing by acting on the various cellular reactions in the fracture callus. J Bone Miner Res 16:671-680

5. Buschmann MD, Gluzband YA, Grodzinsky AJ, Hunziker EB (1995) Mechanical compression modulates matrix biosynthesis in chondrocyte/agarose culture. J Cell Sci 108:1497-1508

6. Choi BH, Woo JI, Min BH, Park SR (2006) Low-intensity ultrasound stimulates the viability and matrix gene expression of human articular chondrocytes in alginate bead culture. J Biomed Mater Res A 79A:858-864

7. Choi BH, Choi MH, Kwak MG, Min BH, Woo ZH, Park SR (2007) Mechanotransduction pathways of low-intensity ultrasound in C-28/I2 human chondrocyte cell line. Proc Inst Mech Eng H J Eng Med 221:527-535

8. Cook SD, Salkeld SL, Patron LP, Doughty ES, Jones DG (2008) The effect of low-intensity pulsed ultrasound on autologous osteochondral plugs in a canine model. Am J Sports Med 36:1733-1741

9. Cui JH, Park K, Park SR, Min BH (2006) Effects of low-intensity ultrasound on chondrogenic differentiation of mesenchymal stem cells embedded in polyglycolic acid: an in vivo study. Tissue Eng 12:75-82

10. Duda GN, Kliche A, Kleemann R, Hoffmann JE, Sittinger M, Haisch A (2004) Does low-intensity pulsed ultrasound stimulate maturation of tissue-engineered cartilage? J Biomed Mater Res B Appl Biomater 68B:21-28

11. Farndale RW, Sayers CA, Barrett AJ (1982) A direct spectrophotometric microassay for sulphated glycosaminoglycans in cartilage cultures. Connect Tissue Res 9:247-248

12. Grodzinsky AJ, Levenston ME, Jin M, Frank EH (2000) Cartilage tissue remodeling in response to mechanical forces. Annu Rev Biomed Eng 2:691-713

13. Gurkan I, Ranganathan A, Yang X, Horton WE Jr, Todman M, Huckle J, Pleshko N, Spencer RG (2010) Modification of osteoarthritis in the guinea pig with pulsed low-intensity ultrasound treatment. Osteoarthr Cartil 18:724-733

14. Harle J, Mayia F (2004) The role of heating, cavitation and acoustic streaming in mediating ultrasound-induced changes of TGF-beta gene expression in bone cells. In: Conference on advanced metrology for ultrasound in medicine (AMUN 2004). Teddington, England

15. Harle J, Salih V, Knowles JC, Mayia F, Olsen I (2001) Effects of therapeutic ultrasound on osteoblast gene expression. In: 16th conference of the European-Society-for-Biomaterials. London, England

16. Heckman JD, Ryaby JP, McCabe J, Frey JJ, Kilcoyne RF (1994) Acceleration of tibial fracture-healing by non-invasive, lowintensity pulsed ultrasound. J Bone Joint Surg 76A:26-34

17. Hsu SH, Kuo CC, Whu SW, Lin CH, Tsai CL (2006) The effect of ultrasound stimulation versus bioreactors on neocartilage formation in tissue engineering scaffolds seeded with human chondrocytes in vitro. Biomol Eng 23:259-264

18. Hsu HC, Fong YC, Chang CS, Hsu CJ, Hsu SF, Lin JG, Fu WM, Yang RS, Tang CH (2007) Ultrasound induces cyclooxygenase-2 expression through integrin, integrin-linked kinase, Akt, NFkappa B and p300 pathway in human chondrocytes. Cell Signal 19:2317-2328

19. Iwashina T, Mochida J, Miyazaki T, Watanabe T, Iwabuchi S, Ando K, Hotta T, Sakai D (2006) Low-intensity pulsed ultrasound stimulates cell proliferation and proteoglycan production in rabbit intervertebral disc cells cultured in alginate. Biomaterials 27:354-361 
20. Kopakkala-Tani M, Leskinen JJ, Karjalainen HM, Karjalainen T, Hynynen K, Toyras J, Jurvelin JS, Lammi MJ (2006) Ultrasound stimulates proteoglycan synthesis in bovine primary chondrocytes. Biorheology 43:271-282

21. Korstjens CM, van der Rijt RHH, Albers GHR, Semeins CM, Klein-Nulend J (2008) Low-intensity pulsed ultrasound affects human articular chondrocytes in vitro. Med Biol Eng Comput 46:1263-1270

22. Kristiansen TK, Ryaby JP, McCabe J, Frey JJ, Roe LR (1997) Accelerated healing of distal radial fractures with the use of specific, low-intensity ultrasound. A multicenter, prospective, randomized, double-blind, placebo-controlled study. J Bone Joint Surg 79A:961-973

23. Lane Smith R, Trindade MC, Ikenoue T, Mohtai M, Das P, Carter DR, Goodman SB, Schurman DJ (2000) Effects of shear stress on articular chondrocyte metabolism. Biorheology 37:95-107

24. Lee DA, Bader DL (1997) Compressive strains at physiological frequencies influence the metabolism of chondrocytes seeded in agarose. J Orthop Res 15:181-188

25. Lee HJ, Choi BH, Min BH, Son YS, Park SR (2006) Lowintensity ultrasound stimulation enhances chondrogenic differentiation in alginate culture of mesenchymal stem cells. Artif Organs 30:707-715

26. Leung KS, Lee WS, Cheung WH, Qin L (2004) Lack of efficacy of low-intensity pulsed ultrasound on prevention of postmenopausal bone loss evaluated at the distal radius in older Chinese women. Clin Orthop Relat Res 427:234-240

27. Mahoney CM, Morgan MR, Harrison A, Humphries MJ, Bass MD (2009) Therapeutic ultrasound bypasses canonical syndecan4 signaling to activate Rac1. J Biol Chem 284:8889-8900

28. Mauck RL, Soltz MA, Wang CC, Wong DD, Chao PH, Valhmu WB, Hung CT, Ateshian GA (2000) Functional tissue engineering of articular cartilage through dynamic loading of chondrocyte-seeded agarose gels. J Biomech Eng 2000:252-260

29. Min BH, Choi BH, Park SR (2007) Low intensity ultrasound as a supporter of cartilage regeneration and its engineering. Biotechnol Bioprocess Eng 12:22-31

30. Mukai $\mathrm{S}$, Ito $\mathrm{H}$, Nakagawa $\mathrm{Y}$, Akiyama $\mathrm{H}$, Miyamoto $\mathrm{M}$, Nakamura T (2005) Transforming growth factor-beta(1) mediates the effects of low-intensity pulsed ultrasound in chondrocytes. Ultrasound Med Biol 31:1713-1721

31. Naito K, Watari T, Muta T, Furuhata A, Iwase H, Igarashi M, Kurosawa H, Nagaoka I, Kaneko K (2010) Low-intensity pulsed ultrasound (LIPUS) increases the articular cartilage type II collagen in a rat osteoarthritis model. J Orthop Res 28: 361-369

32. Nishikori T, Ochi M, Uchio Y, Maniwa S, Kataoka H, Kawasaki K, Katsube K, Kuriwaka M (2002) Effects of low-intensity pulsed ultrasound on proliferation and chondroitin sulfate synthesis of cultured chondrocytes embedded in Atelocollagen $((\mathrm{R}))$ gel. J Biomed Mater Res 59:201-206
33. Noriega S, Mamedov T, Turner JA, Subramanian A (2007) Intermittent applications of continuous ultrasound on the viability, proliferation, morphology, and matrix production of chondrocytes in 3D matrices. Tissue Eng 13:611-618

34. Olkkua A, Leskinen JJ, Lammi MJ, Hynynen K, Mahonen A (2010) Ultrasound-induced activation of Wnt signaling in human MG-63 osteoblastic cells. Bone 47:320-330

35. Parvizi J, Wu CC, Lewallen DG, Greenleaf JF, Bolander ME (1999) Low-intensity ultrasound stimulates proteoglycan synthesis in rat chondrocytes by increasing aggrecan gene expression. J Orthop Res 17:488-494

36. Parvizi J, Parpura V, Greenleaf JF, Bolander ME (2002) Calcium signaling is required for ultrasound-stimulated aggrecan synthesis by rat chondrocytes. J Orthop Res 20:51-57

37. Rutten S, Nolte PA, Korstjens CM, van Duin MA, Klein-Nulend J (2008) Low-intensity pulsed ultrasound increases bone volume, osteoid thickness and mineral apposition rate in the area of fracture healing in patients with a delayed union of the osteotomized fibula. Bone 43:348-354

38. Schumann D, Kujat R, Zellner J, Angele MK, Nerlich M, Mayr E, Angele P (2006) Treatment of human mesenchymal stem cells with pulsed low intensity ultrasound enhances the chondrogenic phenotype in vitro. Biorheology 43:431-443

39. Selmi TAS, Verdonk P, Chambat P, Dubrana F, Potel J-F, Barnouin LP, Neyret P (2008) Autologous chondrocyte implantation in a novel alginate-agarose hydrogel: outcome at two years. J Bone Joint Surg 90:579-604

40. Tien YC, Lin SD, Chen CH, Lu CC, Su SJ, Chih TT (2008) Effects of pulsed low-intensity ultrasound on human child chondrocytes. Ultrasound Med Biol 34:1174-1181

41. Uglow MG, Peat RA, Hile MS, Bilston LE, Smith EJ, Little DG (2003) Low-intensity ultrasound stimulation in distraction osteogenesis in rabbits. Clin Orthop Relat Res 417:303-312

42. Vaughan NM (2009) The potential of pulsed low intensity ultrasound to stimulate chondrocytes in a $3 \mathrm{D}$ model system. University of London, London

43. White D, Evans JA, Truscott JG, Chivers RA (2007) Can ultrasound propagate in the joint space of a human knee? Ultrasound Med Biol 33:1104-1111

44. Yang KH, Parvizi J, Wang SJ, Lewallen DG, Kinnick RR, Greenleaf JF, Bolander ME (1996) Exposure to low-intensity ultrasound increases aggrecan gene expression in a rat femur fracture model. J Orthop Res 14:802-809

45. Zhang ZJ, Huckle J, Francomano CA, Spencer RGS (2002) The influence of pulsed low-intensity ultrasound on matrix production of chondrocytes at different stages of differentiation: an explant study. Ultrasound Med Biol 28:1547-1553

46. Zhang ZJ, Huckle J, Francomano CA, Spencer RGS (2003) The effects of pulsed low-intensity ultrasound on chondrocyte viability, proliferation, gene expression and matrix production. Ultrasound Med Biol 29:1645-1651 